\title{
Motivating factors amongst caregivers of those suffering from dementia: a thematic analysis
}

\author{
Tanvi Sardesai ${ }^{1}$, Neha Bhansali ${ }^{2}$ \\ ${ }^{1}$ Post Graduate student, Department of Psychology, Maniben Nanavati Women's College, Mumbai. \\ ${ }^{2}$ Faculty, Department of Psychology, Maniben Nanavati Women's College, Mumbai. \\ Corresponding author: Tanvi Sardesai \\ Email - sardesai.tanvi94@gmail.com
}

\begin{abstract}
Background: The current study explored the factors that motivate caregivers to continue providing care to their family member suffering from dementia. Maximum variation sampling was employed. In depth interviews were conducted with each caregiver till saturation was reached. A total of five hours of interview data was transcribed verbatim and 75 pages of the transcribed data were analyzed using thematic analysis. 18 themes were identified under the area of motivating factors.

Methodology: The data collection was done through face - to - face in - depth interviews. The sample included was adult female family members of the patient suffering from dementia. They were selected through medical and mental health professionals.

Results: Five hours of audio taped data derived from in depth interview with five caregivers was transcribed verbatim. 75 pages were analysed using thematic analysis. Most of the existing research focuses on the stress and health issues caregivers face. Little research exists about what motivates individuals to choose to provide long term care to their deteriorating family members. Seven areas were explored.

Conclusion: 18 themes were found under motivating factors. These were maternal instincts, reciprocity, responsibility towards family, lack of assistance, lack of an option, caregiver's personality, care and love, viewing caregiving as an opportunity to show concern, concern for patient's safety, patient's attitude towards the caregiver, guilt, viewing the patient as vulnerable, view of oneself, desire for normalcy, identifying with the patient, personal anxiety, final years and hope.
\end{abstract}

ABSTRACT

Key Words: Dementia, caregivers, motivating factors, thematic analysis

(Paper received $-6^{\text {th }}$ July 2019 , Peer review completed $-10^{\text {th }}$ September 2019)

(Accepted $-15^{\text {th }}$ September 2019)

\section{INTRODUCTION}

The care giving process often involves multiple tasks that may be physically, emotionally, socially, or financially demanding [1]. These individuals providing care are usually family, friends, or neighbours and are frequently key resources in the care of patients who would otherwise need institutional care [2].

Caregivers of individuals with dementia are characterized by high levels of stress, burden, drug use, depression, and physical decline. Caregiving spouses, especially wives are particularly vulnerable to negative consequences of caregiving [3]. Yet, they choose to provide long term care. Family caregivers may be motivated to provide care for several reasons: a sense of love or reciprocity, spiritual fulfilment, a sense of duty, guilt, social pressures, or in rare instances, greed [4].

Cicirelli [5] conducted a study to determine the motivating factors for adult children who provide care to older parents despite enduring incredible amounts of burden. There were two motives that Cicirelli focused on: filial obligation and filial attachment. This study was designed to clarify the relationship of obligation and attachment to both the amount of caregiving and the resulting amount of subjective burden. Adult children may com e to feel that it is their duty, obligation or responsibility to help their older parents. 
Caregivers who are motivated by a sense of duty, guilt, or social and cultural norms are more likely to resent their role and suffer greater psychological distress than caregivers with more positive motivations. Caregivers who identify more beneficial components of their role experience less burden, better health and relationships, and greater social support. The negative aspects of caregiving for people with dementia tend to receive most attention, but caring has also been associated with positive feelings and outcomes [6].

A study explored the relation of entrapment, shame and guilt to depression in a group of 70 carers of those with dementia. The experience of entrapment was highly related to depression. Moreover, experiences of shame relating to self-criticism, other people's expectations and the fear of their criticism were significantly related to depression, entrapment and guilt. Guilt focused on the fears of harming others, letting others down and sense of responsibility. Depression in carers may relate in part to feeling trapped in a role but also being vulnerable to criticism and feelings of inadequacy in that role [7].

Factors such as gender, age, marital status, education, ethnicity, and employment status will predict the likelihood of caregiving [8]. A study purporting to explore the impact of background characteristics, exchange patterns, motivating factors and diagnosis of dementia on caregiver reciprocity indicated that adult children of parents with dementia gave more direct instrumental and supervisory care, received more negative and fewer positive exchanges, and reported significantly lower levels of warmth and regard, intrinsic rewards of giving and balance within family caregiving when compared to adult children of parents without dementia [9].

Gender also may influence the caregiving process. A traditional perspective on women's work socializes females to assume duties which are centered in the home and reflect a sense of social obligation [10]. Traditional work roles include the belief that women must expect not only to assume caregiving duties, but also to receive minimal help from male family members.

A study looked at men in the role of elder caregivers. It was found that men reported having found emotional gratification an important motivating factor and they tended to attribute to themselves many affective traits usually associated with the female role [10]. It is seen that for the caregiver, a respite experience is one way to alleviate the negative consequences of caregiving. Caregivers in a study described respite experience as a cognitive process of getting out of the caregiver world and into their own world. In this world, they feel free from the responsibilities and the worries of caregiving-the ideal meaning of respite to these caregivers. Factors influencing the caregivers' abilities to experience this respite include the nature of the pre-illness relationship between the caregivers and their dependent family members, role expectations, the attributes of the available respite services, and time [11].

A study with Swedish population aimed at investigating connections between family caregivers' health and providing care for an ill relative. Results indicated that caregivers' beliefs, experiences of reciprocity, or nonsupport, along with quality of interpersonal relationships and feelings of responsibility and guilt, had a profound impact on their health [12]. Another study using thematic analysis to understand the stressors and resources of caregivers, found that caregivers' primary stressors related to day-to-day patient care and emotional support; secondary stressors included financial hardship, family responsibilities, and social isolation. Caregivers' social, relational, spiritual, and psychological resources mediated the effects of these stressors. Strengthening one resource strengthened others, but the failure of one resource hindered other resources, intensifying the burden [13].

Priorities of people with dementia can be different from those of caregivers. In a study that aimed at understanding these different needs reported that people with dementia had fewer needs compared with the reports of their caregivers and the professionals. The most frequent unmet needs reported by people with dementia, caregivers and professionals were in the areas of daytime activities, company, and psychological distress; however, people with dementia rated psychological distress as the commonest unmet need [14].

A study aimed at understanding end of life care and the effects of bereavement on family caregivers of persons with dementia assessed type and intensity of care provided by family caregivers to persons with dementia during the year before the patient's death and assessed the caregivers' responses to the death. It was found that half the caregivers reported spending at least 46 hours per week assisting patients with activities of daily living and instrumental activities of daily living. More than half the caregivers reported that they felt they were "on duty" 24 hours a day, that the patient had frequent pain, and that they had had to end or reduce employment owing to the demands of caregiving. Caregivers exhibited high levels of 
depressive symptoms while providing care to the relative with dementia, but they showed remarkable resilience after the death. Within three months of the death, caregivers had clinically significant declines in the level of depressive symptoms, and within one year the levels of symptoms were substantially lower than levels reported while they were acting as caregivers [15].

A research paper aimed at reviewing literature related to the experiences of family caregivers after institutionalization of their older relatives found that family caregivers continued their caregiver roles even after institutionalization. A significant decrease was seen in the caregivers' burden after institutionalization. Depression in caregivers, however, was not significantly reduced. After institutionalization, caregivers experienced positive feelings, negative feelings, and mixed feelings [16].

A study about variables involved in predicting dementia caregiver's depression revealed that increases in caregivers' self-efficacy, frequency of leisure activities, and cognitivereappraisal significantly predicted decreases in caregivers' depression over time. It was also seen that increases in stressors were related to increases in depression over time [17].

It was thus seen that caregiving affects lives of the caregivers in innumerable ways. Caregivers experience positive as well as negative emotions towards caregiving. Various factors play a role in predicting caregiving and are responsible for motivating caregivers to care for their family members. The aim of this study was to examine how do the caregivers view their role and the situation that they are in, what motivates them to continue taking care of their family member despite the deteriorating condition and how would they feel if they were to discontinue taking care of the family member.

\section{METHODOLOGY}

\section{Setting}

The study was conducted in Mumbai, Maharashtra. The interviews were conducted at the caregivers' home. In addition to their preference of a familiar place, they were unable to leave their homes as they were looking after their family member.

\section{Sample}

The population was adult female family members of the patient suffering from dementia. The sampling was done till saturation was reached. The sample for the present study consisted of 5 caregivers. The primary inclusion criteria were female adults taking care of their family member suffering from dementia. Diagnoses had been given by psychiatrists and clinical psychologists. Those individuals whose family member had been suffering from dementia for a minimum of one year were selected. This time period allowed for an insight about what makes them continue providing care despite the deteriorating, long term nature of the disorder. The sample was obtained from referrals from medical practitioners and mental health professionals. The sample was selected using a mixture of purposive and snowball sampling methods. One caregiver was the sister of the patient, one was the daughter in law, one was the spouse and the other two were daughters. This maximum variation approach to sampling was used to help incorporate a range of participants sharing a different relationship with the patient for gaining a richer understanding of the reasons they choose to take care and the difference in the emotions the experience.

Patient characteristics: Out of the five patients, three were female and two were male. The patients were all on medication.

\section{Measures used in the study}

A brief socio - demographic questionnaire was used to obtain background information. The questions included age, relationship with the patient, education level, year in which the patient was diagnosed with dementia, family structure, whether the caregiver was currently working or not and the annual income. Participants completed the questionnaire at the beginning of the first interview. It took about $5-10$ minutes to complete.

Interviews: The interviews were simple in depth with probes to encourage the participants to elaborate on specific aspects of their caregiving experience. Interviews began with open ended, non-directive questions. 
Probes like "Tell me what happened next?" and "How did that make you feel?" were utilized to encourage the participants to talk about their experiences. All the interviews began with "What were your thoughts and feelings when your family member was diagnosed with dementia?" As the interviews proceeded, the interview questions became more focused on what motivated the care giver to continue taking care of the family member.

\section{Procedure}

The data collection was done through face-to-face in-depth interviews. The sample included was adult female family members of the patient suffering from dementia. They were selected through medical and mental health professionals. The interview was conducted in one session lasting an hour. An interview schedule was prepared to provide clarity during the interview regarding the areas to be covered. It served as an aid rather than something read out verbatim during the interview. Before any interview began, the participant was given a consent form which included the purpose of the study, assurance regarding confidentiality and how the information will be disseminated.

The consent form was read along with the participant and discussed; with the understanding that the participation was voluntary and the participant could withdraw at any time they felt uncomfortable, that the information shared would be confidential and that the interview will be audiotaped. They were given a brief socio demographic form prior to being interviewed.

In the interview session with each participant, they were asked "What were your thoughts and feelings when your family member was diagnosed with dementia?"

Subsequent conversations with the participants involved questions directed towards the motivating factors. The interview with each participant ended with a debriefing session where the participant's experience of the interview was discussed. It was conducted in English or Hindi or a combination of both depending on the participant's preference. Each interview was scheduled at a time convenient to the participant at their homes.

\section{Research Design}

The design of this study is qualitative, exploratory and descriptive in nature. A qualitative study aids in understanding the experiences of the sample under study and the meanings attributed to different events by them. Caregivers of individuals with dementia are characterized by high levels of stress, burden, drug use, depression, and physical decline. Caregiving spouses, especially wives are particularly vulnerable to negative consequences of caregiving. To obtain an understanding of what makes them continue taking care despite this, a qualitative research design with a contextual epistemological position was used.

\section{Data Analysis}

This exploratory and descriptive qualitative research utilized face-to-face in-depth interviews which were audiotaped and transcribed verbatim. The transcriptions were checked against original audio recording for accuracy. Five hours of data was collected, transcribed verbatim and analysed using thematic analysis which as defined by Braun and Clarke [18] is a method for analysing and identifying patterns of meaning in a data set. It illustrates which themes are important in the description of the phenomenon under study. These themes can contain manifest content and latent content.

Thematic analysis is best suited for elucidating the specific nature of a given group's conceptualization of the phenomenon under study. It forms the implicit basis of many other qualitative methods. Braun and Clarke's model of thematic analysis [19] was used to analyse the transcribed data. According to their model, the process of carrying out thematic analysis can be broken down into six steps, though, as with most qualitative analysis, there was constant going backwards and forwards between the different stages of the analysis to ensure high quality.

The first step involved data familiarisation. Since the semi - structured interview method was used; the data familiarisation began during the data collection process. After each interview, the audio of the first interview session was heard and notes were made for the second interview.

Data familiarisation continued during the transcription process. The second step was the initial coding generation step which involved line-by-line coding or of every four-five lines. 
A code is a label used to describe a line (or few lines) of the transcript. Descriptive coding was used. The coding indicated something that is interesting or important about the data and it involved the researcher systematically working through the data in its entirety. The initial coding captured the essence of a segment of the text.

It was followed by search for themes based on initial coding. It involved identifying the patterns among the different codes, categorizing them into meaningful groups of codes; which resulted in emergence of themes and sub themes. This categorization was done manually on Microsoft Excel.

Thematic analysis is best suited for elucidating the specific nature of a given group's conceptualization of the phenomenon under study. It forms the implicit basis of many other qualitative methods.

Braun and Clarke's model of thematic analysis [19] was used to analyse the transcribed data. According to their model, the process of carrying out thematic analysis can be broken down into six steps, though, as with most qualitative analysis, there was constant going backwards and forwards between the different stages of the analysis to ensure high quality.

The first step involved data familiarisation. Since the semi-structured interview method was used; the data familiarisation began during the data collection process. After each interview, the audio of the first interview session was heard and notes were made for the second interview. Data familiarisation continued during the transcription process. The second step was the initial coding generation step which involved line-by-line coding or of every four-five lines.

A code is a label used to describe a line (or few lines) of the transcript. Descriptive coding was used. The coding indicated something that is interesting or important about the data and it involved the researcher systematically working through the data in its entirety. The initial coding captured the essence of a segment of the text.

It was followed by search for themes based on initial coding. It involved identifying the patterns among the different codes, categorizing them into meaningful groups of codes; which resulted in emergence of themes and sub themes. This categorization was done manually on Microsoft Excel.

\section{RESULTS}

The study was carried out to explore the factors that motivate individuals to care for their family member suffering from dementia and their experiences and emotions.

\section{Length of responses}

Five hours of audio taped data derived from in depth interview with five caregivers was transcribed verbatim. 75 pages were analysed using thematic analysis. Most of the existing research focuses on the stress and health issues caregivers face. Little research exists about what motivates individuals to choose to provide long term care to their deteriorating family members. The study also has personal relevance to the researcher. Seven areas were explored.

\section{Thematic categorization}

41 themes were identified. In the tables the areas, the emerging themes, the codes and the definitions along with examples from the data extract are provided. The areas explored were the onset and initial symptoms, feelings about the condition, feelings towards the patient, feelings about the situation that they are in, the motivating factors, the concerns and ways to cope with the situation.

Onset and initial symptoms. The area of onset and initial symptoms refers to the beginning of the illness and the symptoms presented at the time. There were four themes under this which included 1) Memory related, 2) Mood related, 3) Unusual behaviour and 4) Caregivers' views.

1.1 Memory related. The caregivers spoke about the initial phases where the patients had begun showing deterioration in memory functions. "Initially he started forgetting small things". They spoke the gradual decline in memory, the worsening of their condition. They spoke about the damage done. Caregiver 4 spoke about her mother forgetting names and people. She said: "She had started forgetting our names. She would go and ask the maids who they are and what they are doing here. She was loosening up on her memory". Caregiver 2 spoke about the realization of memory deteriorating before the diagnoses of dementia. 
She said: "When we took her to the doctor he said it is dementia. But we realized that she was forgetting smaller things even before that". Caregiver 3 spoke about how it has been getting worse. She said: "Every year it started becoming more and more. The memory loss. Now it's very bad. He doesn't recognize anyone. Gradually it is becoming worse."

1.2 Mood related. The caregivers spoke about the changes in mood that the patients showed. "She was depressed". They spoke about the mood changes that would come along every day. Caregiver 1 spoke about the patient seeming depressed. She said: "Voh depressed lagti thi. She used to be sad on most days and then sometimes would be happy." Caregiver 3 spoke about mood issues that she saw in the patient. She said: "He has a lot of mood issues. If his mood is not there he will get irritated. He will not eat. Otherwise when he is in a good mood he will talk very nicely".

1.3 Unusual behaviour. The caregivers spoke about the behavioural changes they noticed. They considered these strange. "Used to get very violent". Caregiver 2 spoke about the fear she felt when the patient began to display unusual behavior. She said: "She used to keep searching for her husband who has been dead for many years now. She used to keep calling out to him and looking here and there. We didn't know what's happening. We thought she is going insane or something." Caregiver 5 spoke about the changes they saw in the patient as a person. She spoke about all the behaviours that displayed now were ones they would never have imagined he would. She said: "He used to get very violent. He was a person who never got violent. Forget violent. He never even shouted. He had started giving bad words now. God knows where he got this. Maybe it was the frustration." Caregiver 1 spoke about the strange things that the patient would say. She said: "Sometimes bolegi chor aa gaya. Mere ghar me chori ho gayi. Somebody is taking my property. Toh hum log samajh gaye ki something is there."

1.4 Caregivers' views. The caregivers spoke about their assumptions, understanding and realization about the onset. "Realized ki something is there". Most of the caregivers believed that the condition began only after the death of a close one. Caregiver 1 said "After her husband's death it all started". Caregiver 4 spoke about being unaware initially and decided to take the patient to the doctor when she felt clueless about her behavior. She said:"She started doing very strange things. I didn't know why. Then one day I took to the doctor. That's when we came to know she has dementia."

Feelings about the condition. This area pertains to the emotions and thoughts that the caregiver had towards the condition of the patient. The themes under this area were 1) Uncertainty, 2) Destiny, 3) Focus on the positive aspects and 4) Social embarrassment.

2.1 Uncertainty. The caregivers spoke about the confusion they felt. They described their emotions as surprising, shocking and scary. Caregiver 4 spoke about not expecting something like that. She said: "That time I didn't know. You don't expect something like that na." Caregiver 2 spoke about it as a scary experience. She said "At that time it was scary. We didn't know what was happening." ।

2.2 Destiny. The caregivers blamed and questioned the destiny for the condition of the patient. Caregiver 1 questioned destiny. She said: "Aisa kyu ho haga usko ke saath?" Caregiver 5 blamed destiny for this. She said: "It's just bad luck. What to do now?"

2.3 Focus on the positive aspect. This was a novel theme in case of caregiver 5 . She was emphasized on the positive aspects of the patient's life. She said: "His has led a very healthy life for 84 years. He has everything else. Everyone loves him and treats him with kindness."

2.4 Social embarrassment. The caregivers described the awkwardness they felt. They spoke about feeling ashamed in social situations. "Becomes very embarrassing". Caregiver 4 spoke about the embarrassment she faced when they had guests over for lunch. She said: "She once put laddoos in the paratha stuffing and kept it on the hot plate. She came outside and thought it'll become aloo parathas. We had guests over for lunch that day. I was so embarrassed. I didn't know what to tell them." 
3.Feelings towards the patient. This area pertains to the emotions and thoughts the caregiver has towards the patient. The themes under this were 1) Sympathy, 2) Frustration, 3) Ambiguity, 4) Positive feelings and 5) Accusatory feelings.

3.1 Sympathy. The caregivers spoke about feeling sorry for the patients. "Bohot bura lagta hai". Caregiver 1 spoke about feeling sad and tensed. She said: "Feelings of dukh hota hai. Sad. Tension aata hai." Caregiver 2 spoke about feeling sorry the patient has become dependent. She said: "I feel bad, you know. Everyone person is a self-respecting person. And then you come to a stage where you become so dependent. It's sad". 3.2 Frustration. The caregivers described their feelings of anger, annoyance and irritation. "I get really bugged." Caregiver 1 described the annoyance she feels despite the love. She said: "Two things were there. Ek toh gussa bhi aur pyaar bhi. Kabhi kabhi I felt like giving her one slap and saying chup!" Similarly, the rest of the responses were recorded for the remaining care givers on the dimension of Feelings about the situation that they are in. This area pertains to the emotions and thoughts the caregiver has towards the situation that they are in. the themes included here were- 1) Self-pity, 2) Distress, 3) Positive feelings.

\section{DISCUSSION}

In depth interviews lasting an hour with each caregiver led to five hours of interview data; taken through maximum variation sampling. This provided a chance to hear what caregivers sharing different relationships with the patient had to say about their experiences and emotions related to the caregiving process. The caregivers vented out their emotions and expressed relief about being able to talk about it. It was both inspiring and painful to hear their experiences.

It must be noted that the caregivers were not presented with the themes mentioned in the study. Rather, the themes were derived from what the caregivers said spontaneously to open ended questions. This study's contribution is through the individual accounts that the caregivers offered related to what motivates them and what are the emotions they experience.

Analysis of the transcribed data revealed 18 themes under the motivating factors. These were maternal instincts, reciprocity, responsibility towards family, lack of assistance, lack of an option, caregiver's personality, care and love, viewing caregiving as an opportunity to show concern, concern for patient's safety, patient's attitude towards the caregiver, guilt, viewing the patient as vulnerable, view of oneself, desire for normalcy, identifying with the patient, personal anxiety, final years and hope.

All of the caregivers expressed maternal feelings as one of the reasons that motivated them. They described the patient as being child-like and expressed feeling motherly towards them. A qualitative study by Eileen da Pena on subjective experiences of daughters as caregivers of their frail elderly parents found that many participants felt that there had been a change in the daughter-parent relationship, where the daughters felt that they had somehow become a parent to their parent They described their parent as being like a child, or behaving like one, and thus eliciting "mothering" behaviors from the caregiver. Many of the caregivers shared that either they were like their mothers in some way or another, or that they had learned caregiving behaviors from their mothers which was indicated of caregiving patterns being mostly passed down through the female culture [20].

Reciprocity was another theme found. Most participants in the study expressed their need to return the care that the patient had given them at some point in their lives. They expressed feeling indebted and viewed caregiving as paying the individual back. A study conducted on informal caregiving among women found 'Caregiving is Bi-directional' as one of the themes. Participants in this study viewed caregiving as part of a large reciprocal, interactive, and dynamic partnership [21].

Responsibility towards family was an important theme that was seen in case of all participants. The caregivers stated being a family member as one of the reasons for providing care. Cicirelli [5] conducted a study to determine the motivating factors for adult children who provide care to older parents despite enduring incredible amounts of burden. There were two motives that Cicirelli focused on: filial obligation and filial attachment. It was found that adult children may come to feel that it is their duty, obligation or responsibility to help their older parents.

Lack of assistance was seen as a reason for caregiving by many caregivers. The patients often had no one else to look after them and the caregivers received very little support from their relatives in the caregiving 
process. Lack of an option was a theme seen in case of many of the caregivers. They viewed caregiving as the only option and saw no other choice besides that.

The study by Mendez [21] on informal caregiving among women found that the women in the study viewed choice as irrelevant since giving care was seen as part of a larger marital agreement. The notion of "having a choice" was not seen as part of a woman's paradigm. This theme was caregiving as a negative obligation. Caregiver's personality was a novel theme seen in case of one of the caregivers. The caregiver spoke about her being the kind of person who tended to care for anyone in need of it.

In a study on effects of motivation, roles, coping strategies, and adaptations in relationships and personality on caretaking of elderly parents by midlife couples explored the role of personality factors in caregiving. It was seen that the factors included attitudes toward coresidency; using religious/spiritual beliefs for coping, decision making, and well-being; effect of multigenerational caregiving (taking care of children and elderly parents at the same time); marital status of the caregivers, and having a variety of roles and interests while caregiving [22].

Care and love that the participants felt for their family member suffering from dementia was seen as a major factor that motivated them to look after them. They expressed feelings of love and care and stated various reasons for feeling the same. The attachment that felt as a result of the number of years they spent together, the value they had for the relationship they shared were some of them. Some of the caregivers in the study viewed the caregiving process as an opportunity to show the patient how much they mean to them. They saw this as an opportunity to express their affectionate feelings to the patient.

Most caregivers in the study stated that their concern for the patient's safety was a reason they looked after them. Their concern about the patient's need for security and well-being seemed to motivate them. Some of the caregivers mentioned that the patient's faith in them and the patient's desire to stay with them was one of the reasons they choose to continue taking care of them. Thus patient's attitude towards the caregiver seemed to be a theme in the motivating factors.

Eileen da Pena's study also pointed out that fewer attempts are made to interview the care recipient. As a result, only one point of view seems to exist, and not the whole picture of caregiving [20]. Guilt was seen as a factor influencing many caregivers. Most of the caregivers' statements were indicative anticipatory guilt. The caregivers spoke about the guilt that they would feel if they were to abandon the family member. Some of them expressed guilt regarding their actions in the past towards the patient. The impatience, frustration and anger towards the patient were some of the reasons for their guilt. Regret about not having spent enough time in the past with the family member now suffering from dementia was also seen.

In one study it was observed that caregivers who were motivated by a sense of duty, guilt, or social and cultural norms were more likely to resent their role and suffer greater psychological distress than caregivers with more positive motivations [23].

In the study on informal caregiving among women it was found that spousal caregivers provided care to their husbands regardless of the situation because of external pressures, in the form of guilt from others and self-guilt from if they there were to abandon their husbands [21]. Most of the caregivers viewed the patients as vulnerable. They felt the need to look after the family member because he or she was old and helpless. Many of the caregivers believed that they were the only ones who were capable of looking after the patient. They expressed feeling that no one else was capable of taking care of the patient as they do. This was stated as one of their reasons for looking after their family member.

A novel theme found in case of one caregiver was a desire for normalcy. The caregiver stated her desire to have a normal family. She compared hers to others and expressed that she wished she could have normal conversations with her father as others do. She saw caregiving as an alternative to normalcy. Many of the caregivers identified with the patients. They communicated their concern about old age. They expressed their anxiety about getting old and being in the state that their family member is now in.

Personal anxiety was another theme seen. The caregivers expressed their own anxieties that played a role in motivating them to look after the patient. A novel theme seen in case of one caregiver was that of final years. The caregiver expressed belief that since these were the final years of the patient they must be happy ones. She stated this as one of the reasons motivating her to take care of the patient as these last few years must be as happy as the rest of his life. One reason for this novel theme could be the relationship of the caregiver 
with the patient. She was the spouse. Since the difference between their ages was not much, she probably viewed these as the final years for both of them [24].

Hope was seen as another theme. Some of the caregivers expressed hope that if taken care of the patient may get better.

A study on Hope and connection: the experience of family caregivers of persons with dementia living in a long term care facility found that hope was important and essential for family caregivers of persons with dementia. Several sub-themes were identified including: accepting where they were, living life in the moment, believing in something, standing together, and balancing dual worlds [25].

Other areas that were analysed in the study were onset and initial symptoms, feelings about the condition, feelings towards the patient, feelings about the situation that they are in, the concerns and ways to cope with the situation. The caregivers stated what they observed and felt during the initial phase of the illness. Four themes were seen under this which included aspects which were memory related, mood related, unusual behaviours and the caregivers' views. The caregivers communicated their observations about the loss of memory, irrelevant talking by the patient, aggressive behaviour which was otherwise inconsistent with the patient's personality.

The caregivers also gave an account of the feelings they had towards the condition. These included the themes of uncertainty, destiny, focus on the positive aspects and social embarrassment. A research paper aimed at reviewing literature related to the experiences of family caregivers after institutionalization of their older relatives found that family caregivers continued their caregiver roles even after institutionalization. A significant decrease was seen in the caregivers' burden after institutionalization. Depression in caregivers, however, was not significantly reduced. After institutionalization, caregivers experienced positive feelings, negative feelings, and mixed feelings [26].

The area of feelings towards the patient was also analysed. Caregivers vented out the emotions they felt towards the patients. Sympathy, frustration, ambiguity, positive feelings and accusatory feelings were the themes in this area. It has been seen that caregivers are at an increased risk for feeling angry, anxious, hostile and aggressive. As a possible result, the prevalence of violence is increased in families with dementia patients, with the overall prevalence at 17.4 percent higher than in the general caregiving population [26]. The last area studied was ways to cope with the situation. Support system, personal factors and self-care were themes under this. In a study on dementia caregiving and impact of location of residence on stress, coping, social support and health it was seen that caregivers used more social support seeking coping to deal with their caregiving stress. Caregivers who were more satisfied with support services perceived lower levels of caregiving stress and had a more positive attitude toward their health status [27].

\section{CONCLUSION}

The caregivers interviewed in the study experienced a wide range of emotions. They expressed experiencing positive as well as negative emotions. They were burdened by the demands of the caregiving process and yet they chose to continue. 18 themes were found under motivating factors. These were maternal instincts, reciprocity, responsibility towards family, lack of assistance, lack of an option, caregiver's personality, care and love, viewing caregiving as an opportunity to show concern, concern for patient's safety, patient's attitude towards the caregiver, guilt, viewing the patient as vulnerable, view of oneself, desire for normalcy, identifying with the patient, personal anxiety, final years and hope. Other areas that were analysed in the study were onset and initial symptoms, feelings about the condition, feelings towards the patient, feelings about the situation that they are in, the concerns and ways to cope with the situation.

\section{REFERENCES}

1. Pedlar DJ, Biegel DE. The impact of family caregiver attitudes on the use of community services for dementia care. J Appl Gerontol 1999;18(2):201-21.

2. Kim Y, Schulz R. Family caregivers' strains: comparative analysis of cancer caregiving with dementia, diabetes, and frail elderly caregiving. J Aging Health 2008;20(5):483-503.

3. Corcoran MA. Caregiving styles: A cognitive and behavioral typology associated with dementia family caregiving. Gerontologist 2011;51(4):463-72. 
4. Donovan ML, Corcoran MA. Description of dementia caregiver uplifts and implications for occupational therapy. Am J Occup Ther 2010;64(4):590-5.

5. Keady J, Clarke C, Adams T. Community mental health nursing and dementia care: practice perspectives. McGraw-Hill Education (UK); 2003.

6. Oyebode J, Evans A, Foster N, McDermott P, Pyke P. Creating a new, individualised service. J Dementia Care 1996;4:18-9.

7. Pinquart M, Sörensen S. Helping caregivers of persons with dementia: which interventions work and how large are their effects?. Int Psychogeriatr 2006;18(4):577-95.

8. Ory MG, Hoffman III RR, Yee JL, Tennstedt S, Schulz R. Prevalence and impact of caregiving: A detailed comparison between dementia and nondementia caregivers. The Gerontologist 1999;39(2):177-86.

9. Carruth AK. Motivating factors, exchange patterns, and reciprocity among caregivers of parents with and without dementia. Res Nurs Health 1996;19(5):409-19.

10. Hepburn KW, Lewis M, Sherman CW, Tornatore J. The Savvy Caregiver Program: Developing and testing a transportable dementia family caregiver training program. The Gerontologist 2003;43(6):908-15.

11. Kaye J, Robinson KM. Spirituality among caregivers. Image: J Nurs Scholarship 1994;26(3):218-21.

12. Strang VR, Koop PM, Dupuis-Blanchard S, Nordstrom M, Thompson B. Family caregivers and transition to long-term care. Clin Nurs Res 2006;15(1):27-45.

13. Erlingsson CL, Magnusson L, Hanson E. Family caregivers' health in connection with providing care. Qual Health Res 2012;22(5):640-55.

14. Brodaty H, Donkin M. Family caregivers of people with dementia. Dialog Clin Neurosci 2009;11(2):217-29.

15. Miranda-Castillo C, Woods B, Orrell M. The needs of people with dementia living at home from user, caregiver and professional perspectives: a cross-sectional survey. BMC Health Serv Res 2013;13(1):43.

16. Schulz R, editor. Handbook on dementia caregiving: Evidence-based interventions for family caregivers. Springer Publishing Company; 2000.

17. Chan WC, Ng C, Mok CC, Wong FL, Pang SL, Chiu HF. Lived experience of caregivers of persons with dementia in Hong Kong: a qualitative study. East Asian Arch Psychiatry 2010;20(4):163-9.

18. Braun V, Clarke V, Hayfield N, Terry G. Thematic analysis. Handbook of Research Methods in Health Social Sciences. 2019:843-60.

19. Howitt D, Cramer D. Thematic analysis. Qualitative research and educational sciences: A reader about useful strategies and tools. 2010:179-202.

20. Chan SW. Family caregiving in dementia: the Asian perspective of a global problem. Dement Geriatr Cogn Disord 2010;30(6):469-78.

21. Mendez MF, Cummings JL. Dementia: a clinical approach. Butterworth-Heinemann; 2003.

22. Simpson C, Acton G. Emotion work in family caregiving for persons with dementia. Iss Ment Health Nurs 2013;34(1):52-8.

23. Cooper C, Balamurali TB, Livingston G. A systematic review of the prevalence and covariates of anxiety in caregivers of people with dementia. Int Psychogeriatr 2007;19(2):175-95.

24. Duggleby W, Williams A, Wright K, Bollinger S. Renewing everyday hope: the hope experience of family caregivers of persons with dementia. Iss Ment Health Nurs 2009;30(8):514-21.

25. Covinsky KE, Newcomer R, Fox P, Wood J, Sands L, Dane K, Yaffe K. Patient and caregiver characteristics associated with depression in caregivers of patients with dementia. J Gen Intern Med 2003;18(12):1006-14.

26. Weerd CV, Paveza GJ. Verbal mistreatment in older adults: a look at persons with Alzheimer's disease and their caregivers in the state of Florida. J Elder Abuse Negl 2006;17(4):11-30.

$* * * * * * * * * * * * * * * * * * * * * * * * * * * * * * * * * * * *$

Acknowledgements - Nil

Conflict of Interest - Nil;

Funding - Nil 